\title{
O FORMALISMO MORAL EM KANT: AUTONOMIA E VONTADE
}

\author{
Marcone Costa Cerqueira ${ }^{1}$ \\ Universidade Federal de Santa Catarina (UFSC) \\ (D) https://orcid.org/0000-0003-4539-3840
}

\section{RESUMO:}

Tencionamos, neste artigo, demonstrar os meandros constitutivos do que seja um formalismo moral em Immanuel Kant, tendo como pressuposto teórico sua compreensão de uma teoria da vontade. Este movimento de análise e demonstração teórica terá como fio condutor a ideia de autonomia que permeia a construção da vontade no formalismo kantiano, ou seja, a pressuposição de uma possível autonomia formal da razão é a base na qual se assenta a teoria moral deste pensador. Para execução de nossa pretensão será necessário reconstituir os pontos nevrálgicos do que venha a ser uma teoria da vontade para em seguida analisar os pressupostos kantianos que realçam a centralidade da autonomia da razão na compreensão de uma vontade livre. Desta maneira, o que se pretende por em desnudo é a originalidade kantiana, em relação à tradição que promulga a vontade como marca da liberdade humana, a partir de seu pressuposto de autonomia formal na constituição moral do indivíduo humano.

PALAVRAS-CHAVE: Kant; Formalismo moral; Vontade; Autonomia.

\section{THE MORAL FORMALISM IN KANT: AUTONOMY AND WILL}

\begin{abstract}
:
We intend, in this article, demonstrate the incorporation of what a moral formalism intricacies of Immanuel Kant, whose theoretical assumption their understanding of a theory of will. This motion analysis and theoretical demonstration will have the common theme the idea of autonomy that permeates the construction of the will in the Kantian formalism, the assumption of a possible formal autonomy of reason is the foundation on which rests the moral theory of this thinker. For the implementation of our

\footnotetext{
${ }^{1}$ Doutorando em Filosofia na Universidade Federal de Santa Catarina (UFSC), Santa Catarina - Brasil. E-mail: markantfilos@yahoo.com.br. Bolsista Capes D-S.
} 
claim will need to replenish the hot spots of that may be a theory of will to then analyze the Kantian assumptions that highlight the centrality of autonomy of reason in understanding of free will. Thus, what is intended by in naked is Kant's originality in relation to the tradition which enacts the will as a mark of human freedom, from its formal independence assumption in moral constitution of the human individual.

KEYWORDS: Kant; Moral formalism; Will; Autonomy.

\section{Introdução}

A questão da vontade, ou melhor, da autonomia da vontade, é algo que se inscreve no campo de discussão da ética. Tal discussão se deu por diversos vieses, mas, sempre tendo como mote principal a pressuposição de uma liberdade que se autogoverna enquanto querer livre e autônomo. Apontar as raízes e eventuais ramificações desta discussão é um trabalho árduo e trabalhoso a qualquer intelecto que se ponha a fazê-lo, no entanto, alguns pontos nevrálgicos se mostram como recorrentes na construção das diversas visões que compõem o complexo panorama teórico desta discussão.

De início é necessário, para a execução do trabalho proposto, apresentar a disposição dos termos que caracterizam a teoria da vontade em sua expressão mais acabada na modernidade. Em vista de apresentar esta disposição, não podemos nos furtar a traçar um breve, mas criterioso, itinerário desta teoria em suas linhas mais gerais, sendo obviamente importante apresentar os pontos mais desnudos em cada momento de sua evolução. No campo ético-moral, lugar próprio de sua discussão, as implicações práticas da teoria da vontade são certamente as mais intricadas possíveis, uma vez que uma das principais correntes da ética moderna, a moral kantiana, apresenta suas bases centrais assentadas sobre os pressupostos constitutivos desta teoria. "É, por conseguinte, a simples conformidade com a lei em geral que constitui o princípio de uma boa vontade; e é nisso que consiste o formalismo Kantiano." (PASCAL, 2003, p. 115-116).

De certa forma, é muito fácil começar a discutir um assunto a partir de sua face já delineada, por outro lado é diametralmente difícil realçar os contornos que o tornaram compreensível. É exatamente esse movimento que nos obriga a nuançar os contornos que deram à noção de vontade uma face delineada, partindo de suas reivindicações teóricas basilares e avançando em sentido ascendente à sua formatação final. Em termos gerais a discussão se coloca como uma busca por identificar na história do pensamento a evolução de uma noção ética que corresponda à capacidade de expressar a liberdade necessária para se pensar um agir próprio da racionalidade humana. 
Mesmo que no fundo esta busca se concentre na prerrogativa de uma já definida racionalidade autônoma e livre, percebemos que os traços presentes na evolução da noção de vontade começam por apenas desvelar tal característica da razão. Pensando em como executar o plano proposto, nos sentimos na obrigação de postular que a abordagem assumida para tal fim será a de apontar e criticar os momentos mais destacados da evolução da noção de vontade, tendo como premissa indicar apenas os pontos nevrálgicos que influenciam nossa argumentação. Nosso segundo passo será demonstrar na teoria ética de Immanuel Kant os pressupostos de uma vontade autonomamente livre, para tal, teremos o cuidado de abordar os pontos viscerais que dão ao pensamento kantiano suas matizes de originalidade e sistematização.

Como já dito de início, a amplitude, tanto teórica quanto histórica, do assunto aqui abordado não nos permite uma análise pormenorizada, no entanto, não fugindo à sistematização que se espera de um texto, pretensamente, filosófico, buscaremos a coerência entre argumentação e demonstração. Sendo assim, o que a partir de agora se constituir como falha argumentativa ou demonstrativa, será resultado tão somente do movimento especulativo que anima este artigo.

\section{As estruturas de uma teoria da vontade}

É possível compreender um conceito sem ter primeiro sua definição, mas é impossível dar uma definição sobre determinado conceito sem antes tê-lo compreendido. Seria possível pensar em uma teoria da vontade sem antes tê-la definido, mas seria penosamente difícil defini-la sem antes compreendê-la, diante disto devemos compreender a estrutura de uma teoria da vontade para então defini-la de forma a expressá-la em sua constituição primária. Tal movimento deve nos possibilitar o entendimento da formação estrutural que apresenta o conceito em sua concepção mais básica, permitindo a reconstrução do processo que o delineia.

No caso de uma teoria da vontade a concepção básica se encontra na condição autônoma de escolha feita pelo indivíduo na proposição de suas ações. "A vontade será tematizada quando a atenção se encontrar centralizada no agir do sujeito em si mesmo, independentemente dos resultados e das consequências eventuais desse agir.”(VETÖ, 2005, p. 12). Sendo assim, passamos então a perscrutar as instâncias envolvidas na geração e execução das ações de um indivíduo. Podemos pensar que a condição primeira para uma construção independente de uma ação é o conhecimento das opções que estão envolvidas na escolha, importando saber, no entanto, de forma valorativa, qual a melhor opção a ser escolhida. Postula-se neste caso a existência de uma instância cognitiva que apresenta uma característica de simples discernimento entre melhor ou pior, ou seja, o 
indivíduo reconhece entre duas opções aquela que lhe garante o bem e nunca o contrário.

Zingano (2007, p. 171) apresenta o reconhecimento desta instância como fruto do pensamento socrático, onde a simples faculdade de discernimento entre o bem e o mal já define por si só a ação de escolha do indivíduo. Sendo assim, Sócrates é o representante do intelectualismo, acreditando que só por ignorância alguém escolhe o mal nocivo a si mesmo, e ninguém o faz voluntariamente. Certamente que o intelectualismo puro e simples não é ainda uma teoria da vontade, existe nele a simples constatação de que o indivíduo precisa reconhecer primariamente o bem, para então efetuá-lo. Ou seja, o mal apenas seria feito involuntariamente, sem poder ser tido como uma escolha, sendo tido apenas como resultado de um ato de ignorância, tornando a culpa algo inimputável, o que se torna problemático em uma teoria da vontade. "A dissociação entre a vontade e a força natural do desejo realiza-se na obra de Agostinho. O teólogo cristão deve explicar o pecado e não pode admitir a teoria antiga: ninguém faz o mal voluntariamente." (VETÖ, 2005, p. 16).

O intelectualismo precisa então ser sofisticado, acrescido de uma instância que dê lugar ao impulso do desejo enquanto partícipe da produção da ação em si, mesmo que ele direcione o indivíduo para o mal. O desejo do mal, ou a possibilidade de acatar o desejo do que é nocivo e prejudicial, aponta para a existência de uma falha imputável do indivíduo, uma falha da escolha, não por ignorância apenas, mas, por haver no indivíduo um conflito entre desejos. Tal instância é entendida, segundo ainda Zingano (2007, p. 171), como desiderativa, introduzida por Aristóteles, ela pode ajudar a compor a explicação da ação humana diante da fraqueza de um desejo tendenciado para o mal. Ou seja, mesmo após a constatação da existência de um bem e de um mal o indivíduo opta pelo mal, não por ignorância, mas por fraqueza, caracterizando uma akrasia. ${ }^{2}$

Até agora construiu-se um quadro de extrema inexpressão (ou inexistência) da autonomia propriamente dita, sendo que, a partir da existência apenas destas duas instâncias não se concebe o indivíduo como ativo de suas ações. A partir deste foco fica óbvia a reivindicação de uma instância que eleve o indivíduo a uma condição de autonomia, não apenas discernindo cognitivamente o bem do mal, e nem apenas tomado por desejos conflituosos provenientes de sua capacidade desiderativa.

\footnotetext{
${ }^{2} \mathrm{O}$ termo é geralmente traduzido por como "intemperança" (Éthique de Nicomaque. Texte, traduction, préface et notes par Jean Voilquin. Paris: Garnier Fréres, [19-], p.291) ou "desregramento" (Ética a Nicômaco. Tradução de Edson Bini. 2.ed. São Paulo: Edipro, 2007, p. 20), podendo ainda ser "descontrole". Tal conceito é introduzido e analisado por Aristóteles no Livro VII da Ética Nicomaqueia, sendo claramente uma análise crítica a partir da ideia socrática, já mencionada, sobre a execução de uma má ação por parte do indivíduo como fruto da simples ignorância do bem.
} 
Imperiosamente percebe-se a necessidade, para se conceber uma teoria da vontade, de uma instância autônoma que resgate o indivíduo de uma condição de passividade e o conduza no caminho espontâneo da liberdade, sem obviamente, o deixar a mercê de uma situação de estagnação ética. Em sentido amplo esta condição de passividade só é anulada se introduzirmos uma instância que seja fonte de uma escolha autônoma e livre em relação aos desejos existentes. Tal liberdade é expressa por Vetö da seguinte forma:

\begin{abstract}
A liberdade interna significa a liberdade em relação a si próprio, uma relação de 'escolha' para consigo mesmo [...]. Ora, essa relação para consigo mesmo não pode ser um simples desdobramento material; as fissuras interiores da subjetividade não são simples processos mecânicos, elas correspondem a uma fratura. A liberdade interna, a liberdade moral, é vivida como uma divisão violenta, uma cisão dolorosa. Ela traduz a oposição do sujeito a sim mesmo, o combate interno que surge da conscientização da transgressão. (VETÖ, 2005, p. 15)
\end{abstract}

Esta instância autônoma, que reflete e escolhe livremente entre os desejos, e mais, que dá a si mesma uma alternativa diferente das apontadas por fatores externos, é a mola mestra da ideia de vontade entendida como fruto de uma espontaneidade da razão. Razão esta que não se subjuga aos desmandos do impulso desiderativo e nem se limita ao discernimento simples entre bem e mal, mas ao contrário, instaura no homem a condição de arbitrar autonomamente entre os desejos, contrapondo-lhes se necessário. Certamente que nestes termos enxergamos mais desanuviadamente os caminhos que perpassam a construção teórica de uma noção de vontade, postuladas as instâncias que compõem seu caminho, aparece enfim a estrutura na qual se estabelece a teoria da vontade como fruto da disposição racional em vista da liberdade autônoma.

O intelectualismo socrático e o impulso desiderativo aristotélico parecem não satisfazer as reivindicações de uma teoria da vontade que prima pela, já citada, liberdade autônoma de uma ação moral espontânea. O caráter ativo do agir autônomo é resguardado pela independência da vontade diante dos desejos existentes no indivíduo, ou seja, a composição moral da vontade se instaura como instância superior, livre e julgadora dos impulsos do simples desejo empírico. Em sentido amplo consideramos a vontade como estágio no qual a liberdade do indivíduo se exacerba através da contraposição de uma intenção arbitrada racionalmente ante um desejo deterministicamente imposto pela simples natureza desiderativa. Sendo assim, a definição de uma teoria da vontade se pauta pela centralidade da ação livre da razão em determinar uma contraposição autônoma ao determinismo natural dos desejos, aparecendo como instância independente e superior. $\mathrm{O}$ intelectualismo e o determinismo desiderativo são estágios 
inferiores onde a passividade do indivíduo é notória, principalmente na condição dependente da razão frente os impulsos naturais dos desejos.

Por fim, a vontade surge como marca indelével da racionalidade humana abstraída do domínio natural do desejo empírico, é vontade pura e autônoma, marcadamente centrada na necessidade de se resguardar o arbítrio do indivíduo no decurso de seu agir moral. A vontade surge como valorativa em si mesma, ou seja, seu valor moral independe da ação concretizada ou dos meios necessários para tal, ela é a expressão do querer, blindado pela autonomia racional, não maculada pelo assédio do desejo puro e simples. Tomamos aqui a definição do próprio Kant para ilustrar tal condição:

\begin{abstract}
A vontade é uma espécie de causalidade dos seres vivos, enquanto racionais, e liberdade seria a propriedade desta causalidade, pela qual ela pode ser eficiente, independentemente de causas estranhas que a determinem; assim como necessidade natural é a propriedade da causalidade de todos os seres irracionais de serem determinados à atividade pela influência de causas estranhas. (KANT, 1980, p. 127)
\end{abstract}

A atividade autônoma da vontade é fruto da racionalidade que a funda, como apresentamos anteriormente, a passividade gerada pela simples determinação dos desejos é a marca de um agir moral falho e ainda preso a certa animalidade estranha ao homem racional. Posto este expediente, nos ateremos à tarefa de dirimir o já anunciado percurso seguido na construção da teoria da vontade, retomando a premissa de apenas apontar os pontos nevrálgicos de cada momento abordado. Rastrearemos as sofisticações teóricas que contribuíram para a formatação de uma vontade livre do materialismo da ação simples, pautada na incrível expectativa de um querer puramente racional, intencional, formal.

Posta esta sucinta explanação, a formatação de uma vontade livre terá plena conclusão na modernidade, dando sequência à nossa intricada empreitada perscrutando os altissonantes estrondos causados pela busca da vontade autônoma na modernidade, mais especificamente na obra magistral de Immanuel Kant, onde o formalismo, a autonomia e a liberdade da vontade encontram refúgio em uma teoria que garante guarida segura e munição farta.

\title{
2. A autonomia da vontade no formalismo ético de Kant
}

Kant irá marcar com traçado claro sua inclinação formal através do intuito de firmar bases puramente racionais na discussão ética da fundamentação da vontade. Ele irá proceder na execução de tal objetivo tomando como escudo e broquel a razão prática, responsável por nos dar a orientação na execução de nossas ações. "Os princípios de uma vontade 
pura que Kant almeja examinar são os princípios da razão prática que, a seu ver, podem efetivamente determinar a nossa vontade independentemente das inclinações e desejos naturais [...]." (RAWLS, 2005, p. 173). A teoria kantiana da vontade usa ainda a bitola metafísica nos trilhos da pura intencionalidade, não em um sentido pejorativo, claro, mas no sentido de se manter no campo da distinção entre material e formal, principalmente no sentido de ser impermeável a qualquer influência externa. Como aponta Vetö:

Kant, como sabemos, considera a vontade a mais alta realidade do mundo. $\mathrm{O}$ valor da vontade corresponde à pureza de sua intenção; ora, a pureza moral da intenção é deduzida a partir de sua pureza metafísica. [...]. O alcance moral da vontade corresponde à sua independência em relação a qualquer móvel moral exterior, heterônomo, mas a autonomia moral da vontade provém de sua autonomia metafísica. Kant interroga-se sobre o que é uma vontade pura, sobre o que é uma vontade boa e, por trás dessa questão, quase se perfila a conclusão: a vontade enquanto tal, a vontade que é apenas a vontade, é a boa vontade. (VETÖ, 2005, p. $204-205$ ).

A sofisticação trazida por Kant se alocará na promulgação de uma vontade puramente racional, uma boa vontade regida por seu próprio arbítrio, sendo por isso blindada à heteronomia da causalidade natural. " $\mathrm{A}$ boa vontade é a vontade apta a dar a si mesma a lei de seu agir independentemente de todo móvel sensível, não querendo nada além que a forma pura de sua própria legislação."(VAYSSE, 1998, p. 61). Certamente que é necessário ressaltar sua preocupação em não deixar de expor a espontaneidade radical da razão expressa na liberdade da vontade.

Será um tanto quanto paradoxal perceber que em Kant a liberdade se dá através da promulgação do dever, e sendo assim, obviamente o dever dirige a máxima do querer, é liberdade espontânea da razão na objetivação da lei moral. "Toda a amplidão do raciocínio de Kant se resume nesta célebre formula: 'Podes porque deves'. (Du kannst, denn du sollst)." (BENDA, 1961, p. 38). Esta mecânica é essencial para a definição da boa vontade enquanto expressão autônoma da razão prática que estabelece seus próprios princípios na execução do dever.

Certamente esta construção teórica traz uma enorme sanha de ataque ao determinismo moral natural e ao materialismo moral, sendo expressão na liberdade exclusivamente humana por intermédio da razão. Como aponta Zingano:

A noção de vontade boa está contida na noção de dever; ela age por dever e não somente conforme o dever. Para que esta distinção tenha sentido, é necessário distinguir entre princípio do querer e fim da ação; o dever é obediência ao princípio, não à determinação pelos fins. Daqui a razão moral nos faz ver que 
o valor moral, residindo no princípio do querer só é possível em seres racionais, que tomam essa representação como o princípio determinante da ação; o mais alto bem é esse determinar legalmente a ação. (ZINGANO, 1989, p. 41).

A boa vontade é baseada em suas próprias leis é a expressão máxima da autonomia, uma vez que tais leis não são determinadas por seus fins, antes por princípios práticos. Esta disposição é crucial na viragem moral empreendida por Kant em relação à moral clássica. Tal determinação será crucial na definição do traçado moral da teoria kantiana, principalmente em sua pretensão de universalidade. Neste ponto surge a distinção dos princípios práticos em relação às condições subjetivas e objetivas, entre a máxima e a lei prática, distinção esta, dada pelo próprio Kant:

Princípios práticos são proposições que contêm uma determinação geral da vontade, a qual inclui em si várias regras práticas. São subjetivos, ou máximas, quando a condição é considerada pelo sujeito como válida unicamente para a sua vontade; mas são objetivos, ou leis práticas, quando essa condição é reconhecida como objetiva, isto é, válida para a vontade de todo o ser racional. (KANT, 1984, p. 29).

A principiar então pela vontade na condição subjetiva da máxima, os princípios práticos desta vontade devem ser elevados a uma condição objetiva que traduza uma universalidade da vontade expressa na lei prática. Só passando por este crivo da universal-objetivação é que se pode validar a boa vontade. "A única coisa moralmente boa por si mesma, é a boa vontade. Ela é, não por seus sucessos, mas por seu querer mesmo, sua intenção e sua força, a máxima que inspira sua ação.” (VIALATOUX, 1966, p. 17 - 18). Em momento algum, um ente externo heterônomo pode ser princípio gerador da boa vontade, expressa na condição da lei prática.

Sendo assim, o distanciamento entre as ações e os princípios que as impulsionam é aumentado, a vontade dando a si mesma suas leis exprime em suas máximas sua liberdade e autonomia, nada além de seus próprios princípios pode ser sua motivação, se não, será uma má vontade. Este ponto é chave para diferenciar a sofisticação trazida por Kant em vista das demais postulações anteriores da liberdade da vontade. Não é só a valorização moral da intenção, e nem a justa concordância desta intenção com um bem supremo expresso na vontade divina, antes é a capacidade de autolegislação do ser racional como promulgador de seus próprios princípios que dá a autonomia da vontade. Como argumenta Vetö:

A verdadeira originalidade da filosofia moral de Kant não deve ser procurada na defesa de que a vontade seja a autora dessas ações, mas na exigência de que ela seja o princípio de seus princípios. Os fundamentos da metafísica dos costumes passam em revista as grandes doutrinas da filosofia moral desde a 


\begin{abstract}
Antiguidade e consideram-nas insuficientes para mensurar o grande critério da autonomia. Nem a utilidade, nem a felicidade, nem a perfeição, nem a vontade de Deus poderiam conceder suas leis à vontade. A vontade não deve receber suas leis de outrem, mas encontrá-las em si mesma. Ou, mais precisamente: ela não as deve encontrar em si mesma, mas sim dá-las a si mesma ativamente. (VETÖ, 2005, p. 207).
\end{abstract}

A autonomia da vontade não é representada pela simples indiferença às coisas externas, ela vai mais além, é liberdade de dar a si mesma suas leis por seus próprios princípios. Este movimento é radical e visa exatamente dar à vontade a exacerbação de seu caráter autolegislador. Kant quer que a razão prática seja a fonte da autolegislação do ser racional, uma vez que por si só esta razão é capaz de determinar uma vontade, sendo um fundamento contido na razão pura.

"O homem, em virtude de sua natureza, não é unicamente um ser dotado de razão." (KRÜGER, 1961, p. 101). Um ser puramente racional agiria somente segundo sua razão, sua vontade não correria o risco de ser maculada pela intervenção de um ente externo heterônomo apreendido pelos desejos empíricos. Mas o homem, mesmo sendo um ser racional, não o é puramente, ele ainda conta com seus desejos empíricos na hora de forjar sua vontade. Surge o ponto de tensão que dará à filosofia de Kant seu traçado característico, ora, uma vez sendo não apenas racional, o homem precisa de um ponto universalizador da vontade.

Algo que dirija a máxima, a saber, o dever, como já citamos anteriormente, uma vez que a máxima é um principio subjetivo da ação prática. Ou seja, a regra da ação prática da máxima pode se constituir de diversos modos, uma vez que está sujeita à faculdade de desejar do indivíduo. Por isso, a regra da ação prática prescrita na máxima deve ser um imperativo, uma regra estabelecida por dever. Segundo Kant:

\begin{abstract}
A regra prática é sempre um produto da razão, porque prescreve a ação como meio para o efeito, como intenção (Absicht). Mas, para um ser, no qual a razão não é o único princípio determinante da vontade, esta regra é um imperativo, isto é, uma regra que é designada por um dever (Sollen), que exprime a obrigação (Nötingung) objetiva da ação, e significa que, se a razão determinasse inteiramente a vontade, a ação dar-se-ia inevitavelmente segundo esta regra. (KANT, 1984, p. 30).
\end{abstract}

Kant promulga a universalização do dever na figura do imperativo, dado como modo universal para a objetivação das máximas segundo a lei moral. O imperativo é a diretriz segundo a qual a máxima deve responder, sendo que ao mesmo tempo em que ele indica o caminho da universalização, também induz à autorreflexão, tornando a análise da 
máxima uma tarefa de análise dos próprios princípios fundadores da vontade nela contida.

"Ora, podem distinguir-se duas classes de imperativos: os imperativos hipotéticos e os imperativos categóricos."(PASCAL, 2003, p. 120). A diferenciação se dá no âmbito da finalidade da ação, o imperativo hipotético dá à razão uma ação como indispensável para a realização de um determinado fim, enquanto que o imperativo categórico propõe uma ação como indispensável em si mesma, incondicionalmente. Como distingue o próprio Kant:

Os imperativos têm, pois, um valor objetivo e são totalmente distintos das máximas, enquanto princípios subjetivos. Determinam, ou as condições da causalidade do ser racional, enquanto causa eficiente, simplesmente em relação ao efeito $\mathrm{e}$ à capacidade para produzi-lo, ou unicamente à vontade, quer ela seja ou não suficiente para o efeito. Os primeiros seriam imperativos hipotéticos e conteriam simples prescrições de dexteridade (Geschicklichkeit); pelo contrário, os segundos seriam categóricos e unicamente leis práticas. (KANT, 1984, p. 30).

O imperativo categórico indica o já anunciado agir pelo dever, pura e simplesmente, não se relacionando a máxima a algum fim colimado, seja ele subjetivo ou objetivo. Ele é a expressão da razão pura em seu fundamento prático, sendo necessário entender que essa determinação se relaciona à pureza da vontade, independentemente dos meandros materiais de sua execução. "A razão prática pura se expressa no imperativo categórico, e a razão prática empírica, no imperativo hipotético."(RAWLS, 2005, p. 190). Os dados empíricos da ação moral são determinados na máxima, a partir da intenção do indivíduo em estabelecer seu alvo, sendo por isso passível de realização segundo suas possibilidades, assim como no imperativo hipotético, no entanto, a formalização do agir moral determinado no imperativo categórico é puro no sentido de não estar preso a estabelecimentos empíricos, sendo válido por sua universalização.

Será esta distinção a responsável pela definição da condição de lei do imperativo categórico, uma vez que a máxima pode sofrer condicionamento externo dos fins colimados, assim como o imperativo hipotético está sujeito a condicionamentos de realização, a necessidade contida no imperativo categórico lhe dá a condição de lei, ao contrário da contingência contida na máxima e no imperativo categórico. Segundo a definição de Kant:

As máximas são, pois, certamente princípios (Grundsätze), mas não imperativos. Mas os próprios imperativos, quando são condicionados, isto é, quando não determinam a vontade simplesmente como vontade, mas apenas em vista de um efeito desejado, quer dizer, quando são imperativos hipotéticos, são sem dúvida preceitos práticos, mas não leis. Estas últimas 
devem determinar suficientemente a vontade como vontade, ainda antes de eu perguntar se tenho a faculdade necessária para um efeito desejado, ou o que devo fazer para o produzir [...] (KANT, 1984, p. 32)

O imperativo categórico enquanto lei representa a universalidade da vontade na independência de sua necessidade pura, isenta da contingência das influências empíricas e subjetivas. $O$ agente moral que segue este imperativo, esta lei, está agindo de modo a aceitar o formalismo expresso em sua universalidade, a liberdade de aderir a uma lei dada por si mesmo de acordo a uma lei aceita por si mesmo. "A simples forma da lei não pode, portanto provir se não de uma faculdade não-sensível que transcenda simultaneamente todos os fenômenos e seus princípios de causalidade." (HÖFFE, 1993, p. 131).

Tal faculdade é certamente a razão pura prática expressa no imperativo categórico. Surge daí a sua condição de transcendentalidade, a liberdade expressa no formalismo incondicional da lei moral universalizada no imperativo é absoluta por ser totalmente estabelecida por princípios racionais, não presos aos entes heterônomos apreendidos empiricamente. O sujeito moral transcendental é aquele que, em seu agir moral, parte da razão pura, em seu fundamento prático, e impõe sua ação sobre o mundo sensível, contudo sem partir dele como princípio para tal agir, tendo como diretriz o imperativo categórico enquanto regulador dos princípios de suas máximas. Segundo o comentário de Höffe:

Com a liberdade transcendental, o princípio da moral não reside mais como em Aristóteles em um fim supremo (intransponível), na felicidade. A moral toma sua fonte no princípio absolutamente primeiro, o princípio incondicionado de estabelecimento dos fins; o princípio da moral reside no estabelecimento por si mesma dos fins. Nesta perspectiva kantiana, a ideia da responsabilidade da ação humana é toda sua acuidade e sua radicalidade, a saber, a qualidade de liberdade transcendental ou da autonomia da vontade. (IBID, p. 132).

O recorte dado à liberdade moral a partir desta interiorização da intenção terá sua autonomia garantida na adesão a um princípio universalizador da vontade. Nos pensadores cristãos da vontade, como Duns Scotus e Agostinho, tal princípio será uma adesão à vontade divina e sua justiça, uma condição de liberdade em relação ao determinismo sensível da realidade mundana do homem e até mesmo de sua racionalidade. $\mathrm{Na}$ modernidade e, de modo especial, em Kant, a intenção moral se torna expressão da liberdade da vontade na adesão pelo dever à lei moral. Esta se mostra como um imperativo categórico estabelecido pela razão em sua autonomia legisladora, ou seja, "a bondade ou a maldade de uma qualquer vontade não consiste na capacidade, ou não que ela tem de alcançar um 
determinado fim, e sim, somente na intenção que a determina e a informa." (GALEFFI, 1986, p. 137). Uma plena formalidade do querer distinta de seu conteúdo.

\section{Conclusão}

O ápice da liberdade e autonomia da vontade encontra-se não só em seu desprendimento total na intencionalidade do querer, mas antes na promulgação de um princípio que não é dado por nenhum ente externo à própria razão do agente moral. A transcendentalidade da liberdade da vontade a partir da razão prática estabelece o caráter autolegislador da autonomia moral do homem. Este desprendimento do homem em relação aos determinismos de sua natureza instintiva marca o que seja uma total liberdade autônoma da vontade. No entanto, a originalidade kantiana está no fato de ser tal liberdade dada pelo próprio indivíduo que a experimenta, não vindo nem de um ente superior ou de hábitos instituídos pela sociedade ou por obrigação legal.

Uma universalidade que garante a primazia da razão sobre a inclinação natural, um estado de total independência em relação ao determinismo natural dos desejos empíricos, sendo desta forma, podemos argumentar que em Kant a razão ascende à sua condição de autonomia absoluta, principalmente em seu fundamento prático da ação moral no mundo sensível. Este formalismo moral é a marca indelével da filosofia kantiana, sendo daí por diante um paradigma ético-moral que funda toda uma tradição de pensamento. Como não poderia deixar de ser, ela passou por diversos ataques e críticas, mas, sustém-se, assim como as demais grandes correntes filosóficas, como um dos pilares do pensamento contemporâneo no Ocidente.

\section{Referências bibliográficas}

BENDA, Julien. O pensamento vivo de Kant. Tradução de Wilson Veloso. São Paulo: Livraria Martins, 1961.

GALEFFI, Romano. A filosofia de Immanuel Kant. Brasília: Editora Universidade de Brasília, 1986.

HÖFFE, Otfried. Introduction à la philosophie pratique de Kant: la morale, le droit et la religion. 2.ed. Paris: Librairie philosophique J. Vrin, 1993.

KANT, Immanuel. Crítica da razão prática. Tradução de Artur Morão. Lisboa: Edições 70, 1984.

. Textos selecionados/Immanuel Kant; seleção de textos de Marilena de Souza Chauí; traduções de Tania Maria Bernkopf, Paulo Quintela, Rubens Rodrigues Torres Filho. São Paulo: Abril Cultural, 1980. (Coleção os pensadores). 
KRÜGER, Gerhard. Critique et morale chez Kant. Tradução de M. Regnier. Paris: Beauchesne et ses fils, 1961.

LACROIX, Alain. A razão: análise da noção, estudo de textos; Platão, Aristóteles, Kant, Heidegger. Tradução de Márcio Alexandre Cruz. Petrópolis: Vozes, 2009.

PASCAL, Georges. O pensamento de Kant. Tradução de Raimundo Vier. 8.ed. Petrópolis: Vozes, 2003.

RAWLS, John. História da filosofia moral. Organização de Barbara Herman. Tradução de Ana Aguiar Cotrim. São Paulo: Martins Fontes, 2005. ROGOZINSKI, Jacob. $O$ dom da lei: Kant e o enigma da ética. Tradução de Sílvio Rosa Filho. São Paulo: Paulus, 2008.

VAYSSE, Jean-Marie. Le vocabulaire de Kant. Paris: Ellipses, 1998.

VIALATOUX, Joseph. La morale de Kant. Paris: Presses Universitaires de France, 1966.

VETÖ, Miklos. O nascimento da vontade. Tradução de Álvaro Lorencini. São Leopoldo: Unisinos, 2005.

ZINGANO, Marco. Razão e história em Kant. São Paulo: Brasiliense, 1989. Estudos de Ética Antiga. São Paulo: Discurso Editorial, 2007. 